\title{
A comparative study of the efficacy of ultrasonics and extracorporeal shock wave in the treatment of tennis elbow: a meta- analysis of randomized controlled trials
}

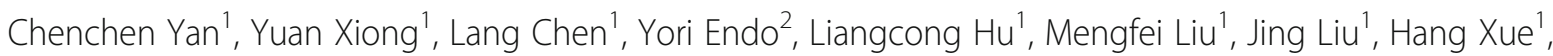
Abudula Abududilibaier ${ }^{1}$, Bobin $\mathrm{Mi}^{i^{*}}$ and Guohui Liu ${ }^{1 *}$

\begin{abstract}
Background: Tennis elbow or lateral epicondylitis is a common source of pain among craftsmen. Although it cannot be completely resolved, extracorporeal shock wave therapy (ESWT) and ultrasonics (US) have been found to be effective for tennis elbow as highlighted in previously published randomized controlled trials (RCTs) and reviews. However, the efficacy of these two therapies in treating tennis elbow is unknown. This meta-analysis compares the effectiveness of ESWT and US in relieving pain and restoring the functions of tennis elbow following tendinopathy.
\end{abstract}

Methods: RCTs published in the PubMed, Embase, Cochrane Library, and SpringerLink databases comparing ESWT and US in treating tennis elbow were identified by a software and manual search. The risk of bias and clinical relevance of the included studies were assessed. Publication bias was explored using funnel plot and statistical tests (Egger's test and Begg's test). The major outcomes of the studies were analyzed using the Review Manager 5.3.

Results: Five RCTs comprising five patients were included in the present meta-analysis. The results revealed a significantly lower VAS score of pain in the ESWT group (1 month: MD =4.47, $p=0.0001 ; 3$ months: $\mathrm{MD}=20.32, p<0.00001$; and 6 months: $\mathrm{MD}=4.32, p<0.0001)$ compared to US. Besides, the grip strength was markedly higher 3 months after the intervention in ESWT ( $M D=8.87, p<0.00001$ ) than in the US group. Although no significant difference was observed in the scores of the elbow function after 3 months of treatment ( $S M D=1.51, p=0.13$ ), the subjective scores of elbow functions were found to be better in the ESWT group (SMD = 3.34; $p=0.0008$ ) compared to the US group.

Conclusions: Although there was no significant difference in the elbow function evaluation scores between ESWT and US, the superiority of the ESWT group in the VAS of pain (both at 1 month, 3 months, and 6 months follow-ups) raised grip strength in ESWT group and the scores for subjective evaluation of efficacy indicated that ESWT offers more effective therapy for lateral epicondylitis than US therapy.

\footnotetext{
* Correspondence: mi19882@163.com; liuguohui@medmail.com.cn ${ }^{1}$ Department of Orthopedics, Union Hospital, Tongji Medical College, Huazhong University of Science and Technology, Jiefang Rd. 1277\#, Wuhan 430022, Hubei, China

Full list of author information is available at the end of the article
}

(c) The Author(s). 2019 Open Access This article is distributed under the terms of the Creative Commons Attribution 4.0 International License (http://creativecommons.org/licenses/by/4.0/), which permits unrestricted use, distribution, and reproduction in any medium, provided you give appropriate credit to the original author(s) and the source, provide a link to the Creative Commons license, and indicate if changes were made. The Creative Commons Public Domain Dedication waiver (http://creativecommons.org/publicdomain/zero/1.0/) applies to the data made available in this article, unless otherwise stated. 


\section{Introduction}

It is well known that lateral epicondylitis (LE), also known as tennis elbow, is one of the most ubiquitous cause of elbow pains among craftsmen [1-3]. It has an incidence of $1-3 \%$ in the general population and constitutes 7 per 1000 primary care consultations annually $[4,5]$. Tennis elbow manifests as a tenderness over the lateral epicondyle of the humerus, as well as a pain on resisted dorsiflexion of the wrist [5, 6]. Although the cause of tennis elbow is often non-specific, it is most commonly associated with workrelated or sports-related overuse of the elbow resulting in hypovascularity in the area [7-9]. Its symptoms can persist for half a year to 2 years, but may resolve naturally in a year or so $[10,11]$. The pain mainly affects the dominant arm, and the severity of this condition tends to be high and persistent for longer duration in female [12].

Although the diagnosis of tennis elbow was standardized many years ago based on its symptoms [5, 13-15], treatments remain largely non-definitive and variable. There are, however, many therapies with beneficial effects, as revealed in some clinical studies [2, 3, 16]. Topical non-steroidal anti-inflammatory drugs (NSAIDs) are mainly prescribed for short-term pain relief, whereas oral NSAIDs are aimed at shortterm improvement in pain relief and function. An extensor fasciotomy was demonstrated to be an effective treatment for refractory chronic lateral epicondylitis [17]. Extracorporeal shock wave therapy (ESWT), ultrasonic therapy (US), corticosteroid injections, physiotherapy, and acupuncture are effective therapies for long-term pain relief and/or functional improvement for patients with tennis elbow [18]. Due to their non-invasive and convenient nature, ESWT and US are considered important adjuvant interventions for treating tennis elbow [19].

Indeed, either of these two treatments is routinely used as the main adjuvant therapy [20, 21]. However, there is no consensus as to which method is the more effective in treating tennis elbow [22]. It is therefore meaningful to make a direct comparison between ESWT and US on their efficacy and safety. This study compares the therapeutic effects of these two therapies in reducing pain intensity, improving mobility in daily activities and self-evaluation of recovery.

\section{Materials and methods}

\section{Searches}

This study was conducted according to the guidelines outlined in the PRISMA (Preferred Reporting Items for Systematic Review and Meta-Analysis). The following databases were explored to extract relevant data: The Cochrane Library, PubMed, MEDLINE, SpringerLink, and OVID. Appropriate randomized controlled trials (RCTs) published between January 2001 and March 2019 were enrolled in this study. The following subject terms were employed in the literature search: tennis elbow, lateral epicondylitis, ultrasonics, and extracorporeal shock wave, and the entry terms related to the subject terms mentioned above were applied in the same way. The specific search employed was as follows: ((()(ultrasonic) AND ultrasonics $))$ AND $(()((()((()(()($ extracorporeal shockwave therapies) or shockwave therapies, extracorporeal) or shockwave therapy, extracorporeal) or therapy, extracorporeal shockwave) or shock wave therapy) or shock wave therapies) or therapy, shock wave) or extracorporeal shock wave therapy) or extracorporeal high-intensity focused ultrasound therapy) or extracorporeal high intensity focused ultrasound therapy) or hifu therapy) or hifu therapies) OR therapy, hifu) or high-intensity focused ultrasound therapy) or high intensity focused ultrasound therapy)) or extracorporeal shock wave $))$ and ((tennis elbow) and ${ }^{(}((()((()(($elbow, tennis) or elbows, tennis) or tennis elbows) or lateral epicondylitis) or epicondylitiden, lateral) or epicondylitis, lateral) or lateral epicondylitis) or epicondylitis, lateral humeral) or epicondylitiden, lateral humeral) or humeral epicondylitis, lateral) or humeral epicondylitis, lateral) or lateral humeral epicondylitis) or lateral humeral epicondylitis))) and ((randomized controlled trial [Publication Type] or (randomized [Title/ Abstract] and controlled [Title/Abstract] and trial [Title/Abstract]))).

\section{Study inclusion and exclusion criteria}

The titles and abstracts of the articles that appeared in the literature search were reviewed independently by two authors to evaluate their eligibility for enrollment. The authors settled any disagreements through discussion. A third person acted as a referee to adjudicate the debate between the investigators. The following criteria were used to select the articles: (1) clinical study was designed and conducted as a randomized controlled trials (RCTs), (2) the study made a comparison between ESWT and US on efficacy for treating lateral epicondylitis, (3) the article was written in the English language or had been translated into English, and (4) the major outcomes measured were the efficacy of pain relief and functional restoration. The exclusion criteria were as follows: (1) the study shared the same data set, (2) the evaluation methods did not address the major outcome, and (3) the participants included in the study had co-morbidities and/or other joint diseases such as hypertension and rheumatoid arthritis. 


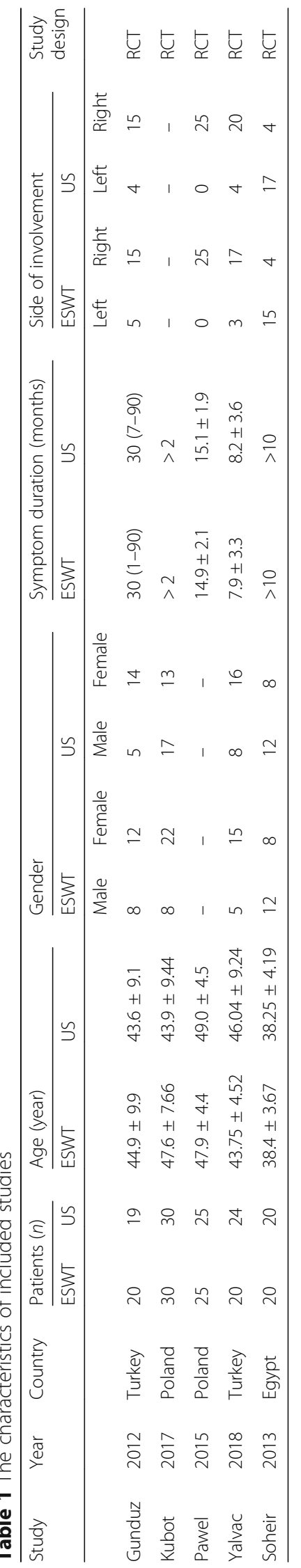




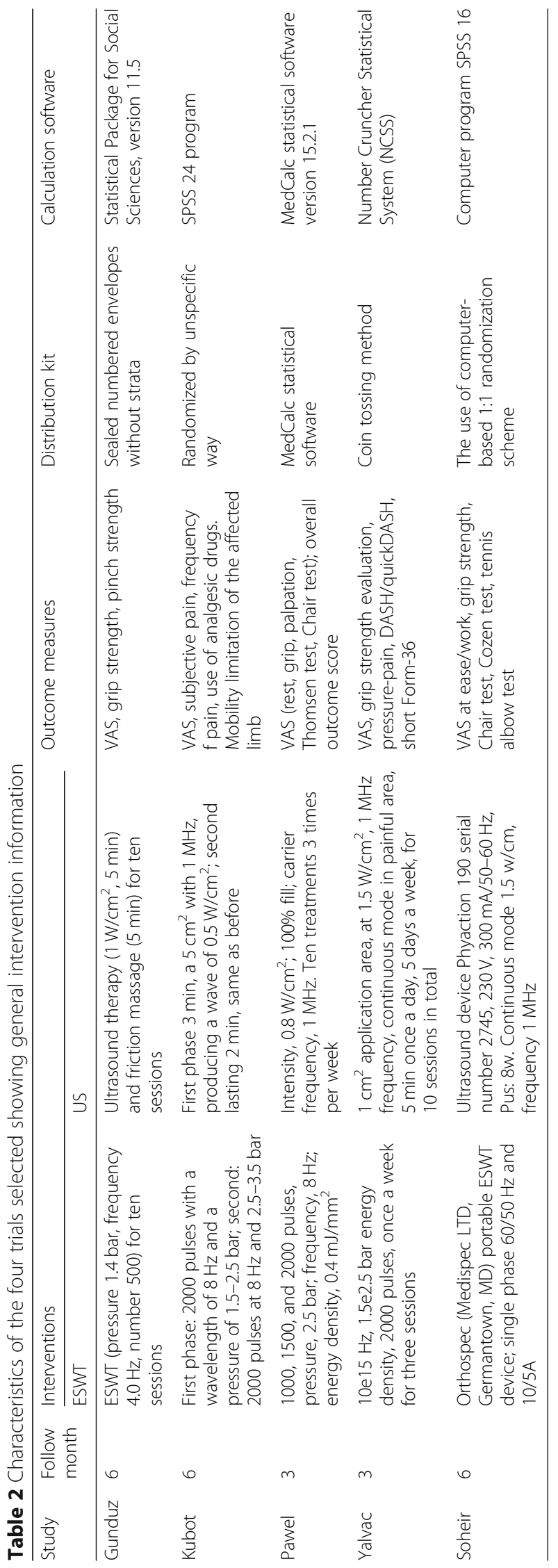




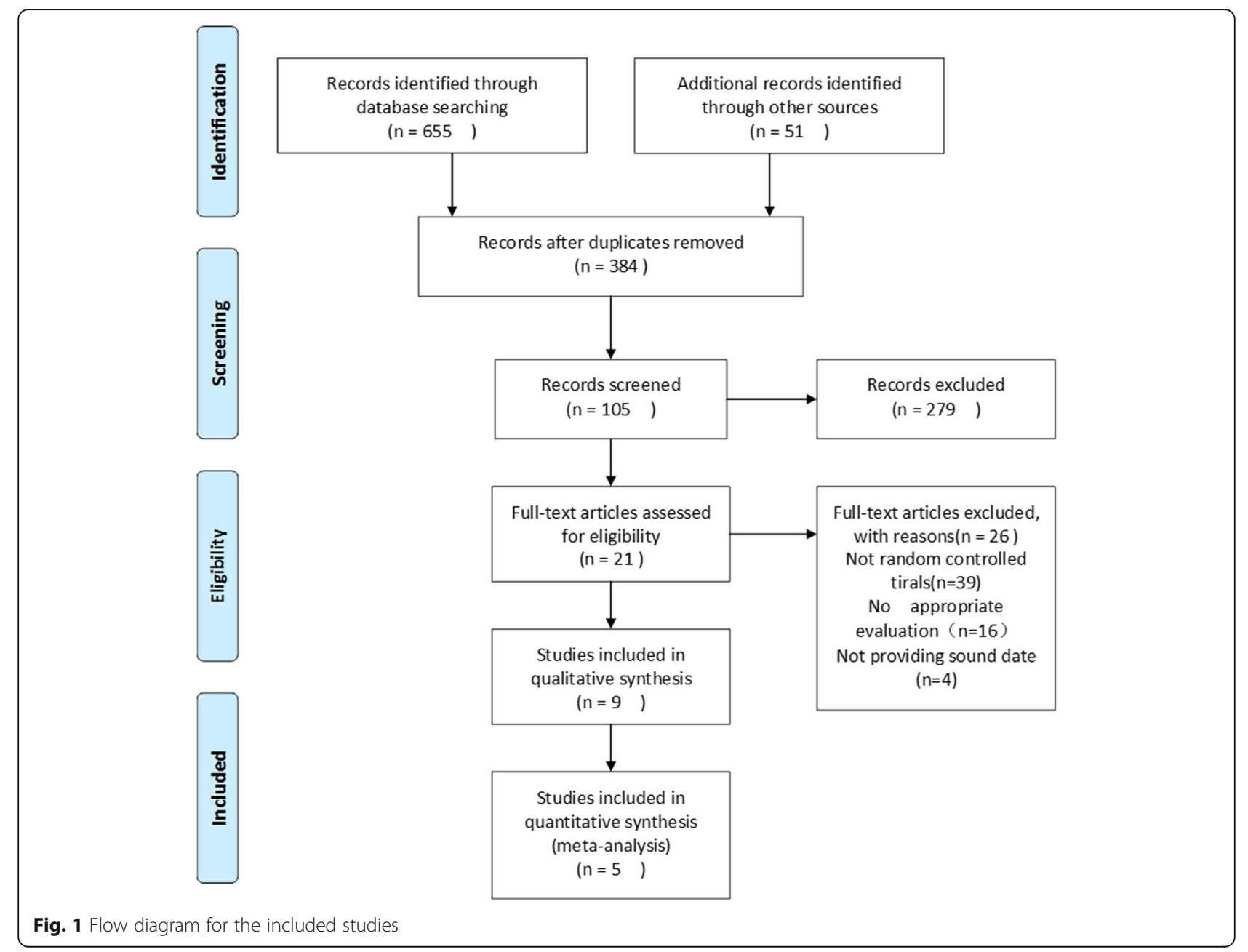

\section{Data extraction strategy}

Based on the pre-determined criteria, the following data was extracted independently from the selected articles by the two authors: background information such as the country of the study, interventions, and major and minor outcomes, and the characteristics of the study subjects such as ethnicity, age, gender, and duration of the symptoms. A third investigator examined the discrepancies in data extraction. The results are provided in Additional file 1.

\section{Quality and risk of bias assessments}

The modified Jadad scale was used to evaluate the quality of the studies, while the Cochrane Handbook for Reviews of Interventions (RevMan version 5.3) was used to assess the risk of bias. The enrolled articles were reviewed by two authors. Each of the studies was assigned a score corresponding to "low," "high," or "unclear" according to the following items: selection bias, performance bias, detection bias, attrition bias, reporting bias, and other biases. Any disagreements between the authors were resolved through discussion.

\section{Data synthesis and presentation}

The RevMan statistical software (RevMan version 5.3) was used to analyze the data extracted from the enrolled articles. In this study, binary data was analyzed to provide a statistical summary of the risk ratios (RR) and the associated 95\% confidence intervals (CI) $(\alpha=0.05$ for the inspection standards). The continuous data were expressed as means and standard deviations (SD), which were then pooled to a weighted mean difference (WMD) and 95\% confidence interval (CI). Heterogeneity was examined by the $I^{2}$ statistic. Outcomes with an $I^{2}$ statistic of $25-50 \%$ were considered to have a low heterogeneity, and $50-75 \%$ a moderate heterogeneity, while $I^{2}>75 \%$ reflected high heterogeneity. For the outcomes with the $I^{2}$ statistic exceeding $50 \%$, subgroup analyses were conducted to investigate the sources of heterogeneity. A statistical significance was indicated by a $p$ value $<0.05$. The 


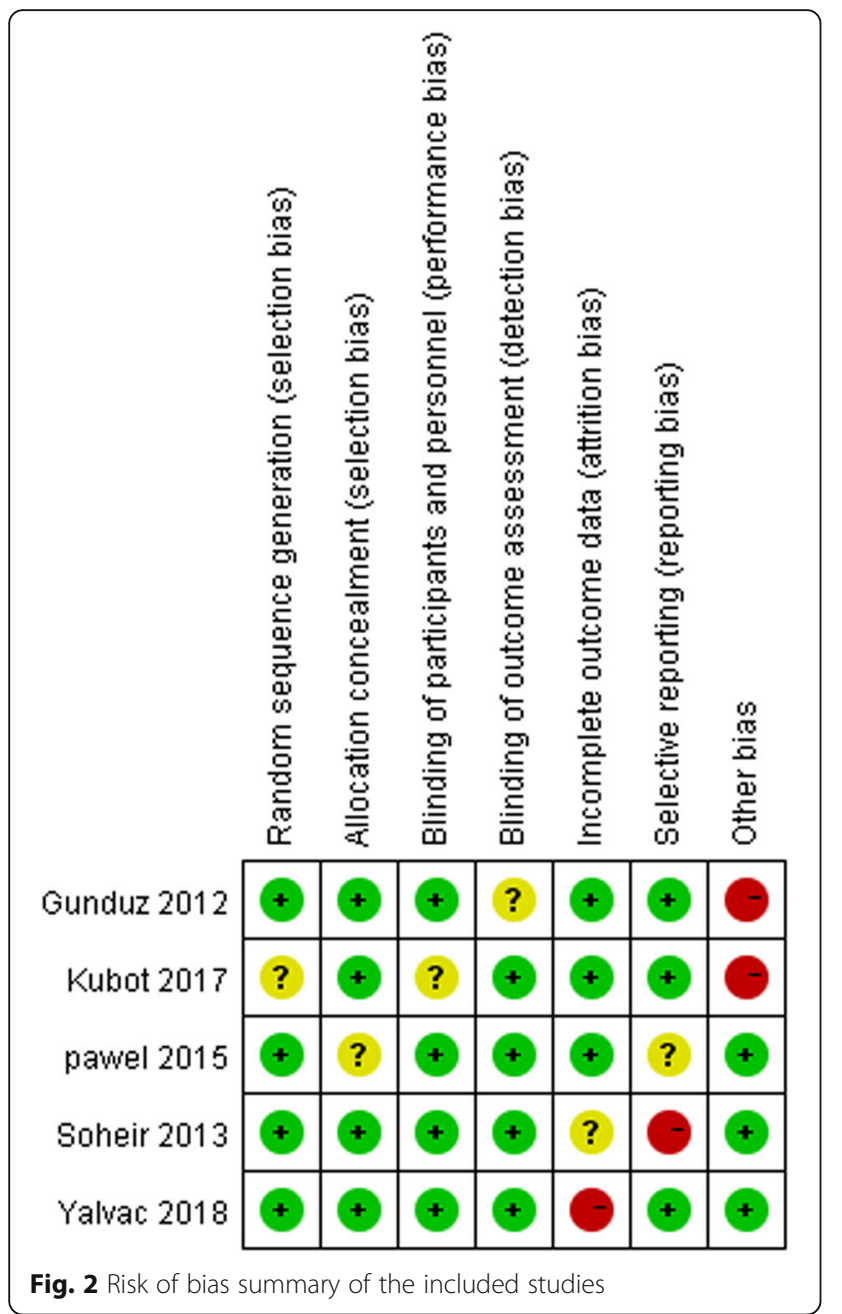

Fig. 2 Risk of bias summary of the included studies fixed effects were employed, for a greater statistical power.

\section{Results}

Literature search and study characteristics

The literature search yielded 706 articles which were considered as potential studies. Three hundred eightyfour publications remained after removal of the duplicates based on the title and abstracts. After the preliminary screening of the 384 studies, a total of 21 manuscripts were further evaluated comprehensively. Finally, 5 articles were found to be eligible for the present meta-analysis. A total of 115 patients were enrolled in the ESWT group, while 118 patients were enrolled in the US group. Tables 1 and 2 summarize the demographic characteristics of the study subjects and quality scores of the studies. Figure 1 shows the literature selection process as described above (see Additional file 2). This study followed the PRISMA 2009 checklist as provided in Additional file 3.

\section{Risk of bias in included studies}

The risk of bias for each of the assessed studies and the results are summarized in (Fig. 2 and Fig. 3). While specific methods for random sequence generation were not mentioned in two trials [23, 24], all of the selected studies claimed a randomized trial design. One trial [25] did not explain their methods for allocation concealment. Blinding processes were not clearly described in two studies $[25,26]$. The one remaining trial [27] was considered to have a high risk due to inadequate blinding.

\section{Pain scores}

The visual analogue scale (VAS) was adopted by all five $[23-26,36]$ trials to evaluate the degree of pain relief. As shown in Fig. 4, there were no differences in the pain

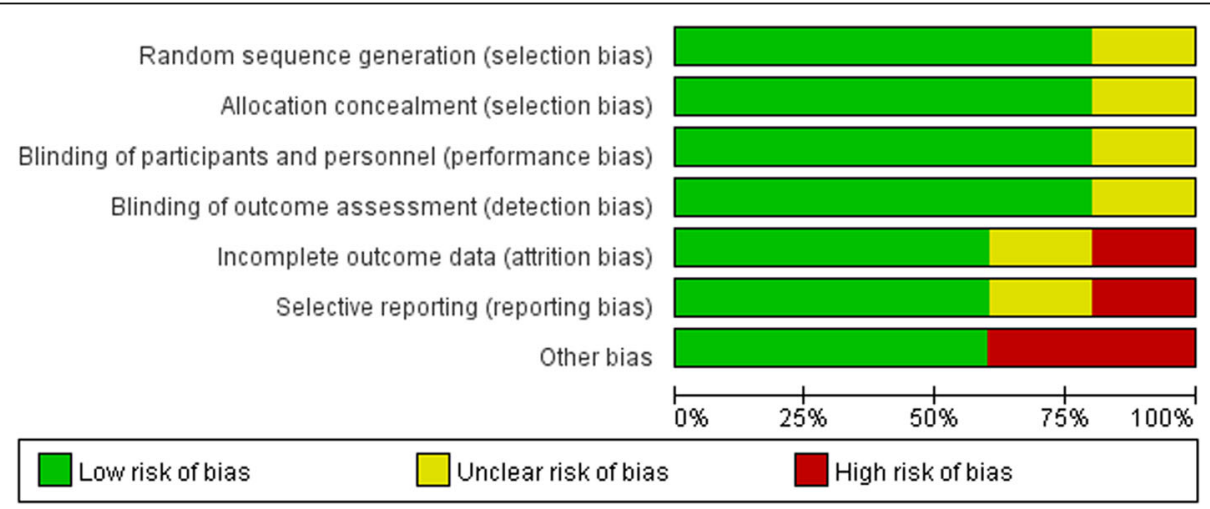

Fig. 3 Risk of bias summary 


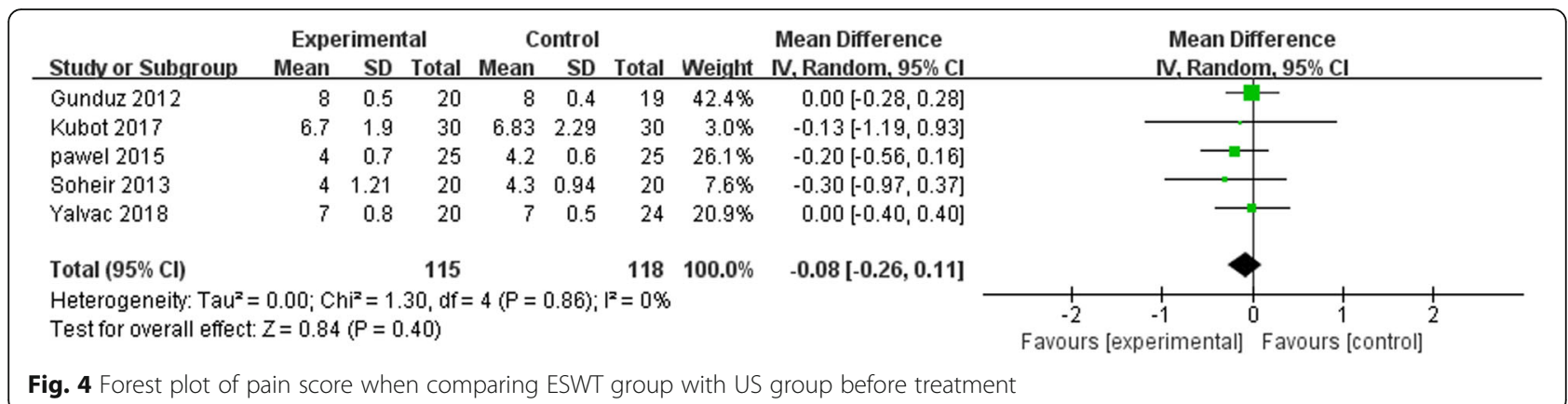

caused by tennis elbow between the treatment groups before the intervention $\left(\mathrm{MD}=0.84, p=0.54, I^{2}=0 \%\right.$ ). However, the ESWT group showed a significantly large reduction in the level of pain after the treatment at 1 month follow-up (MD = 4.47, $\left.p=0.0001, \quad I^{2}=92 \%\right)$ (Fig. 5) while the difference in the pain relief between the treatment groups persisted at 3 months follow-up (MD $\left.=20.32, p<0.00001, I^{2}=98 \%\right)$ in four [23-26] trials (Fig. 6). On the other hand, a remarkable difference $\left(\mathrm{MD}=4.72, p=0.0001, I^{2}=53 \%\right)$ in VAS score existed at 6 months between ESWT group and US group (Fig. 7) in three $[23,24,36]$ trials. These results suggest that the ESWT has a superior efficacy than the US in eliminating the pain in both short- and long-term.

A subgroup analysis based on the race of the subjects was conducted to explore the sources of the high heterogeneity observed in the pain scores across the studies. The results of subgroup analysis for the Polish subgroup (MD $\left.=6.17, p<0.00001, I^{2}=72 \%\right)$ and Turkish subgroup ( $\mathrm{MD}=3.09, p=0.002, I^{2}=92 \%$ ), as well as the total effect $\left(\mathrm{MD}=6.54, p<0.0001, I^{2}=88 \%\right)$ at 1 month followup are shown in Fig. 8. The results for the Polish subgroup (MD $=2.67, p=0.008, I^{2}=93 \%$ ), Turkish subgroup $\left(\mathrm{MD}=1.00, p=0.32, I^{2}=96 \%\right)$, and total effect (MD = $\left.1.84, p=0.07, I^{2}=99 \%\right)$ at 3 months follow-up are summarized in Fig. 9. The results of the subgroup analysis are explained in the "Discussion" section.

\section{Grip strength at 6 months after intervention}

Two $[23,36]$ of the five trials were enrolled to prepare evaluation of grip strength at 6 months after intervention. A comparison was made between ESWT group and US group at 1 and 6 months (Fig. 10). The results revealed that the ESWT group had a better recovery of grip strength compared to the US group $(\mathrm{MD}=2.75$, $\left.p=0.06, I^{2}=66 \%\right) 1$ month after the treatment. Meanwhile, the difference in comparison between ESWT and US group at 6 months after therapy revealed the same outcome $\left(\mathrm{MD}=8.87, p<0.00001, I^{2}=44 \%\right)$. For these reasons, ESWT resulted in better recovery of grip strength in LE patients than US therapy in the long and short run.

\section{Evaluation of the elbow functions}

Three of the five trials $[23,25,26]$ made a comparative evaluation of the elbow functions at follow-ups varying from 1 to 6 months. Elbow function evaluation covered the range of motion of joints, muscle strength, pain, and activities of daily living. Some special function evaluation items included the Chair test, Thomas test, and tennis elbow test. The common time point for follow-up in these trials was 3 months after the treatment (Fig. 11). There were no significant differences in the function scores between the treatment groups at 3 months follow-up (SMD $\left.=1.51, p=0.13, I^{2}=95 \%\right)$, indicating that

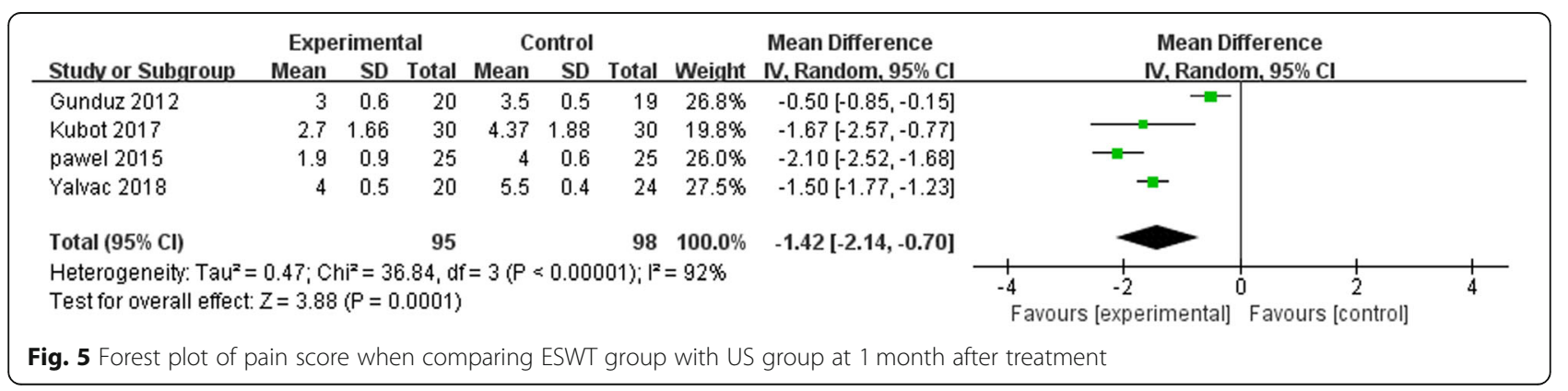




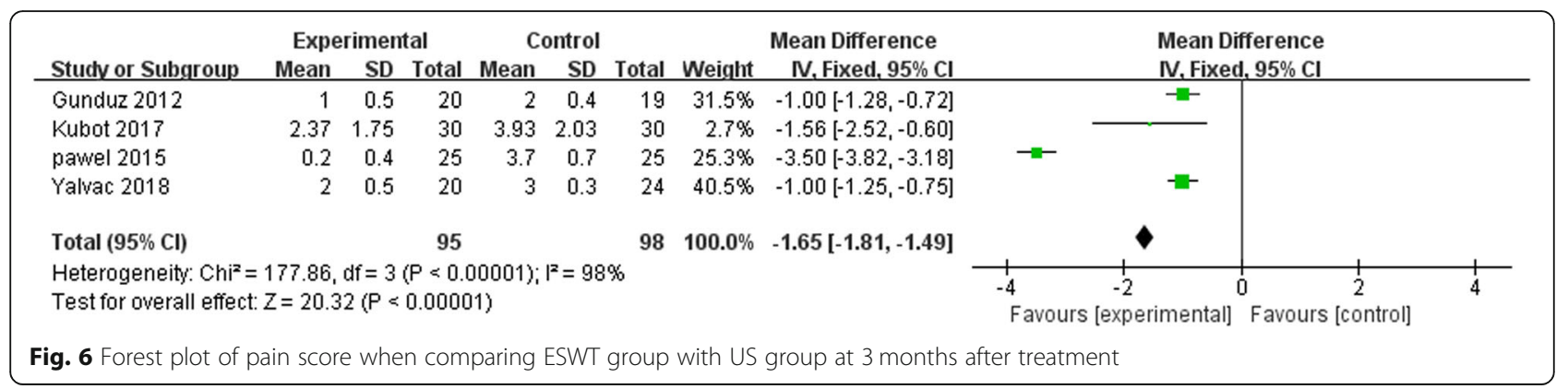

ESWT and US have similar effects on the functional improvement.

\section{Subjective evaluation of therapy efficacy}

Of the four studies, three trials [24-26] performed a subjective evaluation of efficacy in pain relief, restoration of the elbow functions, impact on subjects' ability to work, and so on. There was a significant difference $\left(\mathrm{SMD}=3.34, \quad p=0.0008, \quad I^{2}=51 \%\right)$ between the ESWT and US groups, as shown in Fig. 12; thus, ESWT provided more efficacy in treatment than the US.

\section{Discussion}

Tennis elbow is a common chronic joint condition, which is characterized by pain and tenderness over the elbow $[5,6]$. Limited movements at the elbow joint may severely disrupt daily activities and work, resulting in economic burden to the society [27]. According to previous studies $[2,3,16]$, there are many therapies for tennis elbow, including topical and oral NSAIDs, corticosteroid injections, ultrasonics (US), and extracorporeal shock wave therapy (ESWT). Due to the non-invasive nature and little to no side effects or adverse events associated with ESWT and US, they are preferred by many patients and clinicians as the main adjuvant therapies for tennis elbow [19]. In addition, the efficacy of these two therapies has been supported by a growing number of clinical studies
[28-31]. In most cases, either the US or the ESWT is elected per case because of their similar functionality. In spite of that, there is no consensus as to which therapeutic approach is superior in efficacy [22]. To address this question, the current study compares the efficacy of ESWT and US in the treatment of tennis elbow.

Studies that met the criteria for meta-analysis were examined to extract data on pain relief and functional improvement following ESWT or US treatment in subjects suffering from tennis elbow. In addition, the risk of bias in each of the studies was evaluated via the modified Jadad scale. In this meta-analysis, it was observed that ESWT group had a higher reduction in pain after 1 month of treatment as compared to the US group ( $\left.\mathrm{MD}=3.88, p=0.0001, I^{2}=92 \%\right)$; similar results were obtained after 3 months $(\mathrm{MD}=20.32, p<$ $\left.0.00001, I^{2}=98 \%\right)$ of treatment. These results indicate that ESWT is a superior therapy compared with US in providing a long-term pain relief in tennis elbow. More importantly, these results were consistent with the previous findings by Rompe et al. [28-31]. However, there was high heterogeneity in the pain scores results. Thus, a subgroup analysis was conducted by dividing the short-term and intermediateterm pain scores based on race. It was found that the Turkish subgroup had a higher heterogeneity $(\mathrm{MD}=$ 3.09, $p=0.002, I^{2}=92 \%$ ) than the Polish subgroup $\left(\mathrm{MD}=6.17, p<0.00001, I^{2}=72 \%\right)$ at 1 month follow-

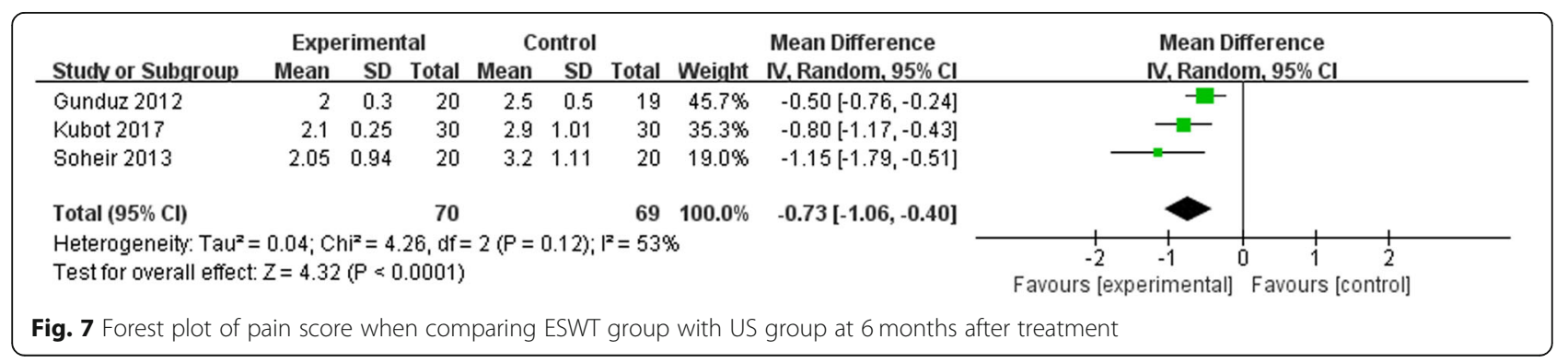




\begin{tabular}{|c|c|c|c|c|c|c|c|c|c|c|}
\hline Studv or Subgroup & \multicolumn{3}{|c|}{ Experimental } & \multicolumn{2}{|l|}{ Control } & & $\begin{array}{l}\text { Mean Difference } \\
\text { IV, Random, } 95 \% \mathrm{Cl}\end{array}$ & \multicolumn{3}{|c|}{$\begin{array}{c}\text { Mean Difference } \\
\text { IV, Random, } 95 \% \mathrm{Cl}\end{array}$} \\
\hline \multicolumn{11}{|l|}{ 2.2.1 Poland } \\
\hline Kubot 2017 & 0.6 & 0.6 & 3 & 3.50 .5 & 19 & $22.5 \%$ & $-2.90[-3.62,-2.18]$ & $\longrightarrow$ & & \\
\hline pawel 2015 & 1.9 & 0.9 & 25 & 40.6 & 25 & $26.7 \%$ & $-2.10[-2.52,-1.68]$ & & & \\
\hline Subtotal $(95 \% \mathrm{Cl})$ & & & 28 & & 44 & $49.1 \%$ & $-2.45[-3.22,-1.67]$ & & & \\
\hline \multicolumn{11}{|c|}{$\begin{array}{l}\text { Heterogeneity: } \text { Tau }^{2}=0.23 ; \mathrm{Chi}^{2}=3.56, \mathrm{df}=1(\mathrm{P}=0.06) ; \mathrm{I}^{2}=72 \% \\
\text { Test for overall effect: } Z=6.17(\mathrm{P}<0.00001)\end{array}$} \\
\hline \multicolumn{11}{|l|}{ 2.2.2 Turkey } \\
\hline Gunduz 2012 & 0.6 & 0.6 & 3 & 3.50 .5 & 19 & $22.5 \%$ & $-2.90[-3.62,-2.18]$ & $\longrightarrow$ & & \\
\hline Yalvac 2018 & 4 & 0.5 & 20 & $\begin{array}{ll}5.5 & 0.4\end{array}$ & 24 & $28.4 \%$ & $-1.50[-1.77,-1.23]$ & $-{ }^{-1}-$ & & \\
\hline Subtotal $(95 \% \mathrm{Cl})$ & & & 23 & & 43 & $50.9 \%$ & $-2.16[-3.53,-0.79]$ & & & \\
\hline \multicolumn{11}{|c|}{$\begin{array}{l}\text { Heterogeneity: } \mathrm{Tau}^{2}=0.90 ; \mathrm{Chi}^{2}=12.87, \mathrm{df}=1(\mathrm{P}=0.0003) ; \mathrm{I}^{2}=92 \% \\
\text { Test for overall effect: } Z=3.09(\mathrm{P}=0.002)\end{array}$} \\
\hline Total $(95 \% \mathrm{Cl})$ & & & 51 & & 87 & $100.0 \%$ & $-2.29[-2.98,-1.60]$ & & & \\
\hline \multicolumn{8}{|c|}{$\begin{array}{l}\text { Heterogeneity: } \mathrm{Tau}^{2}=0.41 ; \mathrm{Chi}^{2}=24.19, \mathrm{df}=3(P<0.0001) ; \mathrm{I}^{2}=88 \% \\
\text { Test for overall effect: } Z=6.54(P<0.00001) \\
\text { Test for subaroun differences: } \mathrm{Chi}^{2}=0.13 . \mathrm{df}=1(\mathrm{P}=0.72) . \mathrm{I}^{2}=0 \%\end{array}$} & $\begin{array}{ccc}-4 & -2 & 0 \\
\text { Favours [experimental] } \mathrm{F}\end{array}$ & Favours [control] & 4 \\
\hline
\end{tabular}

up, and the same relationship was true at 3 months follow-up for the Polish subgroup $(\mathrm{MD}=2.67, p=$ $\left.0.008, I^{2}=93 \%\right)$ and Turkish subgroup $(\mathrm{MD}=1.00$, $\left.p=0.32, I^{2}=96 \%\right)$. However, the study by Smidt et al. [32] revealed that there is a uniform course of recovery for tennis elbow without a clinical heterogeneity, suggesting that a high heterogeneity attributable to the ethnic variation may not be clinically relevant.

In term of the functional recovery, there was no significant difference in the functional scores when the two treatment groups $\left(\mathrm{SMD}=1.51, p=0.13, I^{2}=\right.$ 95\%) were compared, as summarized in Fig. 8. This outcome of function evaluation was different from the others because of the following reasons. The content of function evaluation consisted of varied parts from trial to trial and could be accounted for. Besides, it was difficult to perform assessment quantitatively and in a timely manner due to the complexity of certain operation. Further, the diversity of function assess scores would offset some meaningful differences internally caused by therapies, which exhibited an ultimate smooth trend. Taking these two points into consideration, we did not pay much attention into the different consequence from function evaluation section and the result should also be treated cautiously. Further, a significant difference was observed in the average scores between the ESWT group and US group $\left(\mathrm{SMD}=3.34, p=0.0008, I^{2}=\right.$

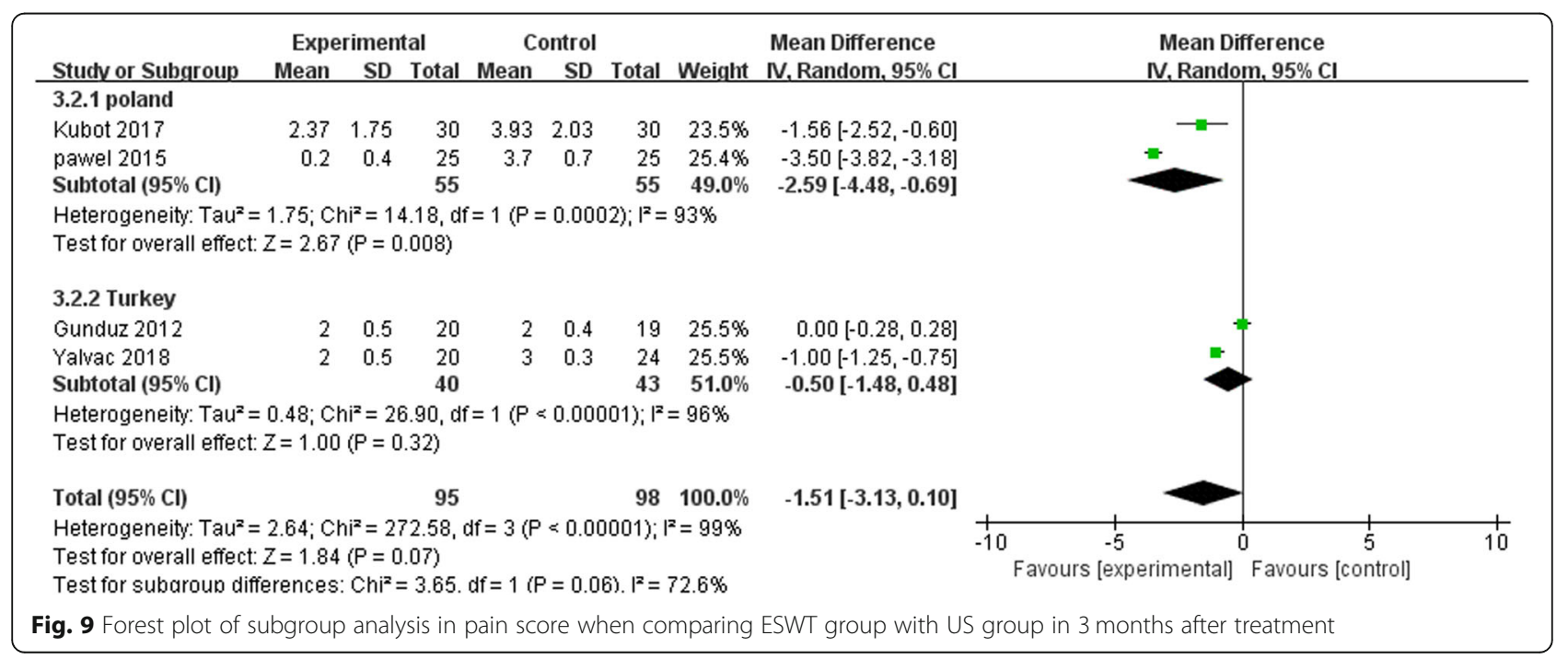




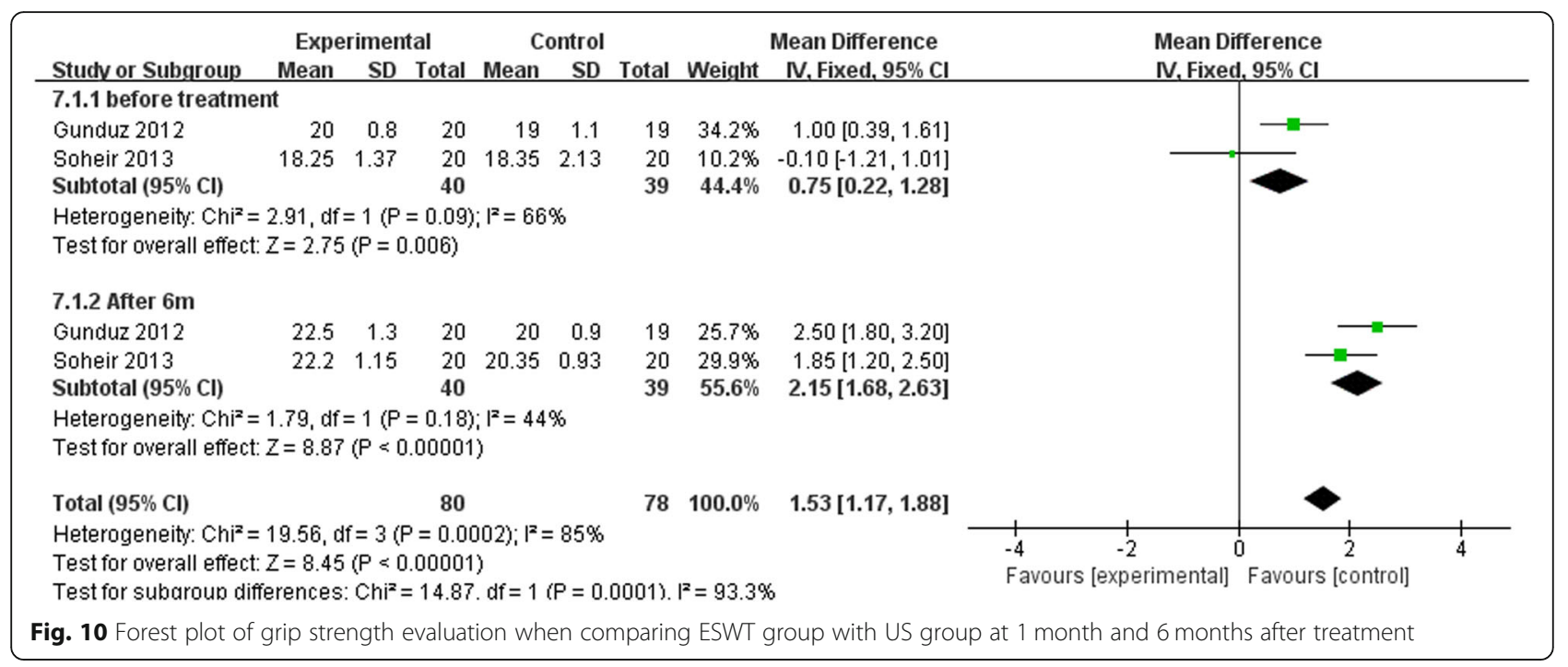

$51 \%)$ after subjective evaluation of efficacy. Therefore, it can be concluded that ESWT is more effective in enhancing recovery from tennis elbow compared to US. A moderate heterogeneity was noted among the studies. A subsequent subgroup analysis revealed that variations in the judgment scores adopted by these trials partly accounted for the observed heterogeneity, for which SMD was used to offset some of the effects.

The higher efficacy of ESWT in pain relief and subjective improvements in tennis elbow may be explained by two mechanisms. Firstly, the energy released by ESWT is greater than that of ultrasonic wave. This would likely enable it to better stimulate pain receptors located in the skin, muscle, connective tissue, bone, and joint, as well as to activate unmyelinated $\mathrm{C}$ fibers and $\mathrm{A}$ delta fibers to initiate the "gated" pain control system, leading to an analgesic effect [33]. Secondly, ESWT causes a large number of tiny bubbles created within tissues, which rapidly expand and burst under the action of shock wave, resulting in high-speed liquid micro-jet and impact effect. This cavitation effect is particularly effective for re-opening occluded microvessels and releasing the soft tissue adhesion at joints [34].

The present study has some shortcomings which need to be highlighted. Firstly, the number of enrolled trials is small which limits the generalizability and contingency of the results. Secondly, the side effects of ESWT and US, such as temporary reddening of the skin, pain, and formation of small hematomas, were not evaluated during follow-up, which differs from the study by Haake et al. [35]. The high heterogeneity among the results weakens the reliability of the results. Therefore, a longer study duration is needed to assess the efficacy of ESWT and US on the tennis elbow function and to explore the optimal therapeutic setting of ESWT.

Nevertheless, the results from this meta-analysis indicate that the efficacy of ESWT is superior to that of US in terms of pain relief and overall recovery in tennis elbow.

\section{Conclusions}

This meta-analysis reveals that ESWT effectively relieves tennis elbow pain at 1 month and 3 months

\begin{tabular}{|c|c|c|c|c|c|c|c|c|c|}
\hline Study or Subgroup & \multicolumn{3}{|c|}{ Experimental } & \multicolumn{2}{|c|}{ Control } & Total & Weight & $\begin{array}{l}\text { Std. Mean Difference } \\
\text { IV, Random, } 95 \% \mathrm{Cl}\end{array}$ & $\begin{array}{c}\text { Std. Mean Difference } \\
\text { IV. Random, } 95 \% \mathrm{Cl}\end{array}$ \\
\hline Gunduz 2012 & 22.5 & 6.05 & 20 & 20 & 5.21 & 19 & $33.8 \%$ & $0.43[-0.20,1.07]$ & \multirow{3}{*}{-} \\
\hline pawel 2015 & 5.5 & 0.6 & 25 & 2.9 & 0.7 & 25 & $32.2 \%$ & $3.93[2.95,4.90]$ & \\
\hline Yalvac 2018 & 32.08 & 14.38 & 20 & 29.29 & 9 & 24 & $34.0 \%$ & $0.23[-0.36,0.83]$ & \\
\hline Total $(95 \% \mathrm{Cl})$ & & & 65 & & & 68 & $100.0 \%$ & $1.49[-0.44,3.42]$ & \\
\hline \multicolumn{9}{|c|}{$\begin{array}{l}\text { Heterogeneity: } \operatorname{Tau}^{2}=2.76 ; \mathrm{Chi}^{2}=43.89, \mathrm{df}=2(\mathrm{P}<0.00001) ; \mathrm{I}^{2}=95 \% \\
\text { Test for overall effect: } \mathrm{Z}=1.51(\mathrm{P}=0.13)\end{array}$} & $\begin{array}{ccccc}-10 & -5 & 0 & 5 & 10 \\
\text { Favours [experimental] } & \text { Favours [control] }\end{array}$ \\
\hline
\end{tabular}




\begin{tabular}{|c|c|c|c|c|c|c|c|c|c|c|}
\hline Study or Subgroup & \multicolumn{2}{|c|}{ Experimental } & \multicolumn{2}{|c|}{ Control } & Weight & $\begin{array}{c}\text { Odds Ratio } \\
\text { M-H, Random, } 95 \% \mathrm{Cl}\end{array}$ & \multicolumn{4}{|c|}{$\begin{array}{c}\text { Odds Ratio } \\
\text { M-H, Random, } 95 \% \mathrm{Cl}\end{array}$} \\
\hline Kubot 2017 & 22 & 30 & 10 & 30 & $44.6 \%$ & $5.50[1.81,16.68]$ & & & & \\
\hline pawel 2015 & 24 & 25 & 7 & 25 & $23.6 \%$ & $61.71[6.96,547.36]$ & & & & \\
\hline Yalvac 2018 & 18 & 20 & 15 & 24 & $31.8 \%$ & $5.40[1.01,28.93]$ & & & & \\
\hline Total $(95 \% \mathrm{Cl})$ & & 75 & & 79 & $100.0 \%$ & $9.67[2.56,36.57]$ & & & & \\
\hline Total events & 64 & & 32 & & & & & & & \\
\hline $\begin{array}{l}\text { Heterogeneity: Tauz } \\
\text { Test for overall effec }\end{array}$ & $\begin{array}{l}0.71 ; \mathrm{Chi} \\
\mathrm{Z}=3.34\end{array}$ & $\begin{array}{l}=4.12 \\
=0.00\end{array}$ & $\begin{array}{l}d f=2(P \\
08)\end{array}$ & $=0.13)$ & $F^{2}=51 \%$ & & $\begin{array}{r}0.001 \\
\mathrm{Fa}\end{array}$ & $\begin{array}{cc}0.1 & 1 \\
\text { perimental] }\end{array}$ & $\begin{array}{c}10 \\
\text { Favours [co }\end{array}$ & 1000 \\
\hline
\end{tabular}

follow-ups compared to US. The subjective evaluation of efficacy showed that ESWT group was superior to US group, although no significant difference was observed in the elbow function scores between the two groups. Together, these results lead to the conclusion that ESWT is a superior adjuvant therapy for tennis elbow compared to US.

\section{Additional files}

Additional file 1: Data extraction excel. (XLSX 22 kb)

Additional file 2: PRISMA 2009 flow diagram word version. (DOC $34 \mathrm{~kb}$ ) Additional file 3: PRISMA 2009 checklist. (DOC 62 kb)

\section{Abbreviations}

ESWT: Extracorporeal shock wave; LE: Lateral epicondylitis; RCTs: Randomized controlled trials; US: Ultrasonic; VAS: Visual analogue scale/score

\section{Acknowledgements}

This study was funded by the National Major R\&D Program of China and supported by the Department of Orthopedics, Union Hospital, Tongji Medical College, Huazhong University of Science and Technology.

\section{Authors' contributions}

CCY and YX contributed equally to this paper. CCY and $Y X$ designed and conceived the experiment. CCY performed the experiments. CCY and LC analyzed the data. CCY and YE wrote the manuscript. LH and ML operated the software. HX and AA carried out the investigation. JL carried out the project administration. GL and BM participated in the sequence alignment and reviewed the manuscript. All of the authors listed have reviewed the manuscript. All authors read and approved the final manuscript.

\section{Funding}

This study was funded by the National Major R\&D Program of China (Item NO.2018YFB1105705).

\section{Availability of data and materials}

We state that the data will not be shared because all the raw data are present in the figures included in the article.

\section{Ethics approval and consent to participate}

Not applicable.

\section{Consent for publication}

Not applicable.

\section{Competing interests}

The authors declare that they have no competing interests.

\section{Author details}

${ }^{1}$ Department of Orthopedics, Union Hospital, Tongji Medical College, Huazhong University of Science and Technology, Jiefang Rd. 1277\#, Wuhan
430022, Hubei, China. ${ }^{2}$ Department of Plastic Surgery, Brigham and Women's Hospital, Harvard Medical School, Boston 02152, USA.

Received: 10 May 2019 Accepted: 24 July 2019

Published online: 06 August 2019

\section{References}

1. Barrington J, Hage WD. Lateral epicondylitis (tennis elbow): nonoperative, open, or arthroscopic treatment? Curr Opin Orthop. 2003;14(4):291-5.

2. Assendelft W, Green S, Buchbinder R, et al. Tennis elbow. Clin Evid. 2004;11: 1633-44.

3. McCracken PN, Sanderman B. Letter: tennis elbow. Lancet. 1974;1:319.

4. Rahman S, Eira V-J, Helena V, et al. Prevalence and determinants of lateral and medial epicondylitis: a population study. Am J Epidemiol. 2006;164: 1065-74.

5. Bisset $L$, Paungmali A, Vicenzino $B$, et al. A systematic review and metaanalysis of clinical trials on physical interventions for lateral epicondylalgia. Br J Sports Med. 2005;39:411-22 discussion 411-22.

6. Assendelft W, Green S, Buchbinder R, et al. Tennis elbow. Am Fam Physician. 2004;16(1):95-102.

7. Nirschl RP, Pettrone FA. Tennis elbow. The surgical treatment of lateral epicondylitis. J Bone Joint Surg Am Vol. 1979;61(6A):832-9.

8. Haahr JP. Physical and psychosocial risk factors for lateral epicondylitis: a population based case-referent study. Occup Environ Med. 2003;60(5):322-9.

9. Ahmad Z, Siddiqui N, Malik SS, et al. Lateral epicondylitis: a review of pathology and management. Bone Joint J. 2013;95-B(9):1158-64.

10. Smidt N, Da VDW, Assendelft WJ, et al. Corticosteroid injections, physiotherapy, or a wait-and-see policy for lateral epicondylitis: a randomised controlled trial. Lancet. 2002;359(9307):657-62.

11. Wilson JJ, Best TM. Common overuse tendon problems: a review and recommendations for treatment. Am Fam Physician. 2005;72(5):811.

12. Castillo-Lozano R, Casuso-Holgado MJ. Incidence of musculoskeletal sport injuries in a sample of male and female recreational paddle-tennis players. J Sports Med Phys Fitness. 2016:57(6):816-21.

13. Peter M. Tennis elbow. There is no proved treatment. BMJ. 2009;339:b5325.

14. Buchbinder R, Green SE, Youd JM, et al. Systematic review of the efficacy and safety of shock wave therapy for lateral elbow pain. J Rheumatol. 2006; 33(7):1351-63.

15. Magosch P, Lichtenberg S, Habermeyer P. Radial shock wave therapy in calcifying tendinitis of the rotator cuff--a prospective study. Z Orthop Ihre Grenzgeb. 2003;141(6):629.

16. Jindal N, Gaury Y, Banshiwal RC, et al. Comparison of short term results of single injection of autologous blood and steroid injection in tennis elbow: a prospective study. J Orthop Surg Res. 2013;8:10.

17. Rayan F, Rao V, Purushothamdas $\mathrm{S}$, et al. Common extensor origin release in recalcitrant lateral epicondylitis - role justified? J Orthop Surg Res. 2010;5:31.

18. Raman J, MacDermid JC, Grewal R. Effectiveness of different methods of resistance exercises in lateral epicondylosis-a systematic review. J Hand Ther. 2012;25(1):5e26.

19. Coombes BK, Connelly L, Bisset $L$, et al. Economic evaluation favours physiotherapy but not corticosteroid injection as a first-line intervention for chronic lateral epicondylalgia: evidence from a randomised clinical trial. Br J Sports Med. 2016;50:1400-5.

20. Kohia M, Brackle J, Byrd K, et al. Effectiveness of physical therapy treatments on lateral epicondylitis. J Sport Rehabil. 2008;17(2):119-36.

21. Nieva EM, Minchev RM, Petrova NS. Radial shock wave therapy in patients with lateral epicondylitis. Folia Med. 2012;54(3):35-41. 
22. Sems A, Dimeff R, lannotti JP. Extracorporeal shock wave therapy in the treatment of chronic tendinopathies []]. J Am Acad Orthop Surg. 2006;14(4):195,

23. Gündüz R, Fã M, Borman P, et al. Physical therapy, corticosteroid injection, and extracorporeal shock wave treatment in lateral epicondylitis. Clinical and ultrasonographical comparison. Clin Rheumatol. 2012;31(5):807-12.

24. Kubot A, Grzegorzewski A, Synder M, et al. Radial extracorporeal shockwave therapy and ultrasound therapy in the treatment of tennis elbow syndrome. Ortop Traumatol Rehabil. 2017;19(5):415-26.

25. Lizis $P$. Analgesic effect of extracorporeal shock wave therapy versus ultrasound therapy in chronic tennis elbow. J Phys Ther Sci. 2015;27(8): 2563-7.

26. Bestami Y, Mesci Nilgün, Geler Külcü Duygu, et al. Comparison of ultrasound and extracorporeal shock wave therapy in lateral epicondylosis. [J] Acta Orthop Traumatol Turc. 2018;52:357-62.

27. Murley R. Tennis elbow: conservative, surgical, and manipulative treatment. Br Med J. 1987;294(6575):839-40.

28. Rompe JD, Hope C, Küllmer K, et al. Analgesic effect of extracorporeal shock-wave therapy on chronic tennis elbow. J Bone Joint Surg Br. 1996:78:233-7.

29. Razavipour M, Azar MS, Kariminasab MH, et al. The short term effects of shock-wave therapy for tennis elbow: a clinical trial study. Acta Inform Med. 2018:26:54-6.

30. Król P, Franek A, Durmała J, et al. Focused and radial shock wave therapy in the treatment of tennis elbow: a pilot randomised controlled study. J Hum Kinet. 2015;47:127-35.

31. Bayram K, Yesil H, Dogan E. Efficacy of extracorporeal shock wave therapy in the treatment of lateral epicondylitis. North Clin Istanb. 2014;1:33-8.

32. Smidt $\mathrm{N}$, Lewis $\mathrm{M}$, Hay EM, et al. A comparison of two primary care trials on tennis elbow: issues of external validity. Ann Rheum Dis. 2005;64:1406-9.

33. Gerdesmeyer L, Wagenpfeil $S$, Haake M, et al. Extracorporeal shock wave therapy for the treatment of chronic calcifying tendonitis of the rotator cuff: a randomized controlled trial. JAMA. 2003;290:2573-80.

34. Luh J-J, Huang W-T, Lin K-H, et al. Effects of extracorporeal shock wavemediated transdermal local anesthetic drug delivery on rat caudal nerves. Ultrasound Med Biol. 2018;44:214-22.

35. Haake M, Böddeker IR, Decker T, et al. Side-effects of extracorporeal shock wave therapy (ESWT) in the treatment of tennis elbow. Arch Orthop Trauma Surg. 2002;122:222-8.

36. RezkAllah SS, AboEl Azm SN, El Gendy AM. Extra corporeal shock wave therapy is superior to ultrasound in the treatment of lateral epicondylitis: an experimental study. Ultrasound Med Biol. 2013;2:171-8.

\section{Publisher's Note}

Springer Nature remains neutral with regard to jurisdictional claims in published maps and institutional affiliations.

Ready to submit your research? Choose BMC and benefit from:

- fast, convenient online submission

- thorough peer review by experienced researchers in your field

- rapid publication on acceptance

- support for research data, including large and complex data types

- gold Open Access which fosters wider collaboration and increased citations

- maximum visibility for your research: over $100 \mathrm{M}$ website views per year

At BMC, research is always in progress.

Learn more biomedcentral.com/submissions 